anatomical structure. Just how far it is or is not vascular in normal man is not completely clear. In certain animals it is a-vascular and in man this is probably so. The abundant vasa vasorum supply the adventitia rather than the intima.

In the cornea, lipoid deposition is the last event in a series of changes following chemical damage of various kinds. Let the chemical be called $X$. The chemical $X$ does not itself cause these deposits for they never appear unless the cornea vascularises, and then only occasionally. The vessels or something which accompanies them are responsible for the lipoid accumulation. Invasion of the cornea by wandering cells alone does not account for the lipoid scars because all central non-vascular lesions heal with the aid of wandering cells but deposition of lipoid is never a feature of these scars. Thus the sequence of events is clear up to a point in the cornea.

In atheroma the sequence of events is not yet known. It is often assumed or suggested on the basis of animal experiments that the intimal lipoid deposits are directly due to hypercholesterinaemia. Our observations on the cornea indicate that a hypothetical substance or substances $\mathrm{X}$, may, by reaching the intima in the first place (or, if a vitamin, by failure to reach it) cause sufficient damage to bring in capillaries as part of an inflammatory reaction. This vascularisation, which is often seen in atheroma, may be followed by regression and by deposition of lipoid. This is merely speculation but, granted that the intima is normally non-vascular, it does not disagree with the facts.

\title{
ANOMALOUS PUPIL REACTIONS
}

BY

\author{
B. G. Edelston, M.D.ED., B.CH. \\ TUBERCULOSIS OFFICER, KENT COUNTY COUNCIL
}

ONE of the most instinctive, protective actions of human behaviour is the raising of the hands to the eyes to guard them from an excessive sudden access of light; and this action is in health accompanied by the reflex shutting down of the aperture of the pupil in a miosis that is both protective and utilitarian. The pupil of Argyll Robertson is a strange paradox : but a stranger one still is the actual dilatation of the pupils to the stimulus of light which occurs, very rarely, in tabetic states. The three cases described below were seen in the course of the work at Chest Clinics over a period of ten years, and it is thought that their rarity and the obscure pathological mechanism of their causation may be found of clinical and speculative interest. 
CASE 1.-A young man, aged 30, was referred to the clinic because of attacks of vomiting and abdominal pain, thought to be due to chronic tuberculous peritonitis. The patient had a most expressionless countenance. He stated that he felt as though he were walking upon cotton-wool, had difficulty and pain on passing water, and was experiencing some weakness of sight.

Clinically there was no evidence of tubercle. His knee and Achilles reflexes were absent, and there was well-marked Rombergism. The pupils were small in size, equal, and centrally placed. They dilated to an appreciable degree to light stimulus. Ophthalmoscopy shewed early optic atrophy.

He admitted primary infection ten years before. The Wassermann reaction was strongly positive.

CASE 2.-This patient, aged 59 years, was referred as a case of possibly tuberculous pleurisy with effusion. He complained of pain in the left chest and of darting pains in his shins, severe but fleeting. Clinically the whole of the left chest was dull to percussion, especially at the base, and a moderately large effusion occupied the left hemithorax. As the heart was displaced towards the side of the effusion and not away from it, it was inferred that there was most probably a tumour within the left thorax, counteracting and overcoming the tendency of the fluid to push the heart to the opposite side. Exploration shewed a typical pleuritic exudate. X-rays confirmed the clinical findings, and demonstrated a more or less homogeneous opacity extending from the apex to the base, but slightly less dense at the upper zones than at the lower. The right lung was normal except for the presence of some slight compensatory emphysema.

All his reflexes were present with the single exception of the Achilles jerk. The pupils were moderate in size, centrally placed and equal. Stimulation by light produced a small but definite dilatation of the pupils. The patient resolutely denied specific infection.

The Wassermann reaction was strongly positive. Some days after he was first seen he attended the clinic again, and admitted that he had had a primary sore 30 years before, at the age of 29 years.

He shortly afterwards died, and autopsy was stated to have shewn the presence of a new growth in a soft caseous condition. Owing to exigencies of time and place the examination was unfortunately inconclusive, for no histological investigation was carried out, nor any search for the spirochaeta pallida. It seems at least possible, however, that the new growth was a gumma, and it is well known that specific disease predisposes to tuberculous infections. Gummata of the lungs are rare, and they are usually multiple and encapsuled, but single ones do occur. It is pertinent 
to note that this patient had been receiving pot. iodid. and liq. hydrarg. perchlor. for some time before his death, and this treatment may have had a specific effect upon the pulmonary growth.

CASE 3.-A young woman, aged $27 \frac{3}{4}$ years, was referred by a National Service Medical Board for opinion upon her chest and lymphatic glands. Clinical and radiological examinations were negative, but in the course of systemic investigation it was noticed that the left pupil was larger than its fellow and was immobile to light, but shewed slight, slow contraction to convergence. There was no loss of sight, and the discs were normal. No Rombergism was present nor loss of sensation, but all superficial reflexes were absent with the exception of the biceps jerks, which were feebly present. It was stated that the parents had noticed this peculiarity when the patient was aged ten, and a diagnosis of juvenile tabes had been made at an eye hospital.

Serological tests were negative. As the patient seemed to be a perfectly healthy young woman, normal in every other respect, it was considered that the phenomenon was an example of the myotonic pupil-a condition usually confined to the female sex, constituting no disability, and unrelated to either neurosyphilis or tabes, although a pupil reacting to accommodation but not to light may occur also in encephalitis, diphtheria or as a hereditary condition, probably due to interference in the tract from the superior corpus quadrigeminum to the anterior nucleus of the third nerve nucleus (Letheby Tidy). Absence of any history of such diseases at or before the age of ten years. seemed to prove the innocent character of this defect in photogenic reaction.

\section{Summary}

Three cases of anomalous pupil reactions to light are described, two of specific aetiology in patients with tabes dorsalis, and one in a healthy young woman with an inborn error in reflex action to light. It may be that the pupils of spinal miosis, in cases where that condition is present, are already so contracted that they camot be further diminished by any stimulus of light, however strong, but that the accommodation contraction reflex, having a different reflex arc, has a more powerful effect. But if the pathogenesis of reflex iridoplegia is obscure, that which caused these phenomena must be equally so, and it would be interesting and instructive to know the opinions of ophthalmologists and neurologists upon the problem of their- recondite causation.

The writer wishes to express his thanks to Dr. Constant Ponder, County Medical Officer of Health, for permission to publish an account of these cases. 